\title{
Modelling the biogeochemical cycles of elements limiting primary production in the English Channel. I. Role of thermohaline stratification
}

\author{
Alain Ménesguen*, Thierry Hoch \\ Laboratoire de Chimie et Modélisation des Cycles Naturels, Direction de l'Environnement et de l'Aménagement du Littoral, \\ Institut Français de Recherche pour l'Exploitation de la Mer (IFREMER), Centre de Brest, BP 70, F-29280 Plouzané, France
}

\begin{abstract}
This paper presents the general framework of an ecological model of the English Channel. The model is a result of combining a physical sub-model with a biological one. In the physical submodel, the Channel is divided into 71 boxes and water fluxes between them are calculated automatically. A 2-layer, vertical thermohaline model was then linked with the horizontal circulation scheme. This physical sub-model exhibits thermal stratification in the western Channel during spring and summer and haline stratification in the Bay of Seine due to high flow rates from the river The biological sub-model takes 2 elements, nitrogen and silicon, into account and divides phytoplankton into diatoms and dinoflagellates. Results from this ecological model emphasize the influence of stratification on chlorophyll a concentrations as well as on primary production. Stratified waters appear to be much less productive than well-mixed ones. Nevertheless, when simulated production values are compared with literature data, calculated production is shown to be underestimated. This could be attributed to a lack of refinement of the 2-layer box-model or processes omitted from the biological model, such as production by nanoplankton.
\end{abstract}

KEY WORDS: Ecological box-model - Thermohaline stratification - English Channel · Primary production

\section{INTRODUCTION}

Many studies on modelling are devoted to shelf seas such as the English Channel, largely because their ecosystem dynamics are influenced in part by terrestrial inputs. Increased nutrient concentrations in rivers lead to disturbances in the coastal environment, known as eutrophication phenomena. Red tides, anoxic events and macroalgal proliferations are among the most noticeable. In the case of the English Channel, horizontal transport characteristics are now better known and modelled (Salomon \& Breton 1993). Longterm circulation generates strong gyres, especially in the Normand-Breton Gulf, whereas trajectories in the central part of the eastern Channel appear to be almost straight. On the vertical dimension and during the summer, the water column in the western Channel is divided into 2 layers, separated by a thermocline. In

•E-mail: amenesg@ifremer.fr the eastern Bay of Seine, high river flows induce the formation of a quasi-permanent strong halocline.

Existing data on chemical and biological components can be used to construct an ecological model of the English Channel whose basic purpose is to simulate main spatial and temporal trends in the primary production of this shelf sea. Modelling studies are scarce for the area: only Agoumi (1985) and Hoch et al. (1993) set up ecological models of the entire Channel, whereas Riou (1990) restricted her model to the North Brittany coast and Ménesguen et al. (1995) to the Bay of Seine alone. Moreover, Agoumi's and Riou's models did not include the latest improvements in the calculation of horizontal residual currents, and dealt only with the nitrogen cycle. In contrast, the first approach to nitrogen cycle modelling by Hoch et al. (1993) did not take into account vertical stratification. Therefore, the purpose of the present study is to improve simulation of primary production of the English Channel further, by incorporating the cycle of $2(\mathrm{~N}, \mathrm{Si})$ or $3(\mathrm{~N}, \mathrm{Si}, \mathrm{P})$ 
potentially limiting nutrients, and using realistic horizontal residual circulation along with a 2-layer description of stratified areas.

\section{THE MODEL}

Modelling the vertical structure. As shown by Agoumi (1985), Riou (1990) and Tett (1990), an initial step in modelling the effects of physical vertical structure on ecology can be achieved thanks to integral, 2 layer models such as that of Niiler \& Kraus (1977). The main principles of these models follow:

- Specific mass of sea water $(\rho)$ is linearly dependent on temperature $(T)$ and salinity $(S)$ of sea water:

$$
\rho=\rho_{0} \cdot\left[1-\alpha \cdot\left(T-T_{0}\right)+\beta \cdot\left(S-S_{0}\right)\right]
$$

where $p_{0}$ is the specific mass of sea water at reference temperature $T_{0}$ and salinity $S_{0} ; \alpha$ is the thermic linear dilatation coefficient; and $\beta$ is the haline linear densification coefficient.

The dynamic aspect of these specific mass variations is described by the derived notion of 'buoyancy':

$$
B=g \cdot(\alpha T-\beta \cdot S)
$$

where $g$ is the gravitational acceleration.

- Wind stress at the sea surface creates a downward turbulent flux of kinetic energy, which tends to mix the solar heat and freshwater received through the surface over a 'surface layer'; such an increase of surface layer thickness can be considered as an entrainment of bottom water into the surface layer, with a vertical entrainment velocity $\left(w_{\text {eb }}\right)$.

- Current friction on the bottom creates an upward turbulent flux of kinetic energy, which tends to mix the bottom water properties over a 'bottom layer'. This can be considered as an entrainment of surface water into the bottom layer, with a vertical entrainment velocity $\left(w_{e s}\right)$.

The resulting vertical structure is made of 2 homogeneous layers ('surface' and 'bottom' layer) between which remains the pycnocline region. When a strict, 2 layer model is applied here, the thickness of this intermediate pycnocline region vanishes. For a water column of total depth $H$, the thermohaline model then requires the computation of 5 independent state variables: $h$, thickness of the surface mixed layer $(m)_{i} T_{s}$, temperature of the surface mixed layer $\left({ }^{\circ} \mathrm{C}\right) ; S_{\mathrm{s}}$, salinity of the surface mixed layer (psu) $T_{b}$, temperature of the bottom mixed layer $\left({ }^{\circ} \mathrm{C}\right)_{i} S_{\mathrm{b}}$, salinity of the bottom mixed layer (psu).

The differential equations governing these 5 state variables are as follows (Riou 1990):

$$
\frac{\mathrm{d} h}{\mathrm{~d} t}=w_{\mathrm{eb}}-w_{\mathrm{es}}
$$

$$
\frac{\mathrm{d} T_{\mathrm{s}}}{\mathrm{d} t}=\frac{w_{\mathrm{eb}}}{h} \cdot\left(T_{\mathrm{b}}-T_{\mathrm{s}}\right)+\frac{-L+I_{0, t}-I_{h, t}}{\rho_{0} \cdot C_{\mathrm{p}} \cdot h}
$$

where $L$ is total thermic losses at the sea surface; $C_{p}$ is the specific heat of sea water at constant pressure $I_{z, l}$ is the flux of solar radiation penetrating at depth $z$ ( $I_{0 . t}$ at depth $0, I_{h, t}$ at depth $h$, etc.) and time $t, I_{z, t}=$ $I_{0, t} \cdot \exp \left(-k_{\text {ext }} \cdot z\right) ; k_{\text {ext }}$ is the light extinction coefficient of sea water.

$$
\frac{\mathrm{d} S_{\mathrm{s}}}{\mathrm{d} t}=\frac{W_{\mathrm{eb}}}{h} \cdot\left(S_{\mathrm{b}}-S_{\mathrm{s}}\right)-\frac{F \cdot S_{\mathrm{s}}}{\rho_{0} \cdot h}
$$

where $F$ is the freshwater flow rate $\left(\mathrm{kg} \mathrm{m}^{-2} \mathrm{~s}^{-1}\right)$

$$
\begin{aligned}
\frac{\mathrm{d} T_{\mathrm{b}}}{\mathrm{d} t} & =\frac{W_{\mathrm{es}}}{H-h} \cdot\left(T_{\mathrm{s}}-T_{\mathrm{b}}\right)+\frac{I_{h, t}-I_{H, t}}{\rho_{0} \cdot C_{\mathrm{p}} \cdot(H-h)} \\
\frac{\mathrm{d} S_{\mathrm{b}}}{\mathrm{d} t} & =\frac{W_{\mathrm{es}}}{h} \cdot\left(S_{\mathrm{s}}-S_{\mathrm{b}}\right)
\end{aligned}
$$

Computation of the entrainment velocities $w_{\text {es }}$ and $W_{\text {eb }}$ are of critical importance; as per Niiler \& Kraus (1977) and Riou (1990), the following expressions have been retained:

$$
W_{\mathrm{eb}}=\frac{g \cdot \alpha}{B_{\mathrm{s}}-B_{\mathrm{b}}} \text {. }
$$

$\left(\frac{2 \cdot m_{\mathrm{W}} \cdot U_{\mathrm{W}}^{3}}{g \cdot \alpha \cdot h}-\frac{B_{0}+\left|B_{0}\right|}{2 \cdot g \cdot \alpha}+\frac{B_{0}}{g \cdot \alpha}-\frac{I_{0, t}+I_{h, t}}{\rho_{0} \cdot C_{\mathrm{p}}}+\frac{2}{\rho_{0} \cdot C_{\mathrm{p}} \cdot h} \cdot \int_{0}^{h} I_{z, l} \cdot \mathrm{d} z\right)$

where $m_{\mathrm{W}}$ is the faction of wind stress energy used in vertical mixing, $m_{\mathrm{W}}=0.5$ (non-penetrating convection); $U_{\dot{W}}^{\dot{*}}$ is the wind stress, $U_{\dot{W}}^{*}=U_{10} \sqrt{\rho_{a} \cdot \mathrm{C}_{10} / \rho_{0}} ; U_{10}$ is the wind velocity at $10 \mathrm{~m}$ above sea surface $\left(\mathrm{m} \mathrm{s}^{-1}\right) ; C_{10}$ is the drag coefficient, $C_{10}=\left(1+0.03 \cdot U_{10}\right) \times 10^{-3} ; \rho_{a}$ is the specific mass of air $\left(\mathrm{kg} \mathrm{m}^{-3}\right), \rho_{\mathrm{a}}=1.293 \times 273 / T_{\mathrm{a}}$ i $T_{\mathrm{a}}$ is the air temperature $(\mathrm{K}) ; B_{0}$ is the buoyancy flux at sea surface; $B_{\varsigma}$ is the buoyancy of the surface mixed layer; $B_{b}$ is the buoyancy of the bottom mixed layer.

$$
\begin{aligned}
& w_{\mathrm{es}}=\frac{g \cdot \alpha}{B_{\mathrm{s}}-B_{\mathrm{b}}} \\
& \left(\frac{2 \cdot m_{\mathrm{C}} \cdot U_{\mathrm{C}}^{* 3}}{g \cdot \alpha \cdot(H-h)}-\frac{I_{h,}+I_{H, t}}{\rho_{0} \cdot C_{\mathrm{p}}}+\frac{2}{\rho_{0} \cdot C_{\mathrm{p}} \cdot(H-h)} \int_{h}^{H} I_{z, t} \cdot \mathrm{d} z\right)
\end{aligned}
$$

where $m_{C}$ is the fraction of current stress energy used in vertical mixing, $m_{\mathrm{C}}=0.07 ; U_{\mathrm{C}}^{*}$ is current friction velocity, $U_{\mathrm{C}}=U_{\mathrm{C}} \sqrt{C_{\mathrm{D}}} \cdot\left(C_{\mathrm{m}} / C_{\mathrm{mo}}\right) ; U_{\mathrm{C}}$ is mean current velocity over the water column $\left(\mathrm{m} \mathrm{s}^{-1}\right) ; C_{d}$ is the drag coefficient, $C_{d}=2.1 \times 10^{-3} ; C_{m}$ is the tidal coefficient; $C_{m 0}$ is the reference tidal coefficient $(=70)$.

The thermal losses at the sea surface $(L)$ can be expressed as follows:

$$
L=R_{\text {water }}-R_{\text {alr }}+C_{\text {evap }}+C_{\text {conv }}
$$

where $R_{\text {water }}$ is water radiation $\left(\mathrm{W} \mathrm{m}^{-2}\right), R_{\text {alr }}$ is air radiation $\left(\mathrm{Wm}^{-2}\right), C_{\text {evap }}$ is evaporation $\left(\mathrm{Wm}^{-2}\right)$ and $C_{\text {conv }}$ is convection.

Water radiation:

$$
R_{\text {water }}=\varepsilon_{\mathrm{w}} \sigma \cdot T_{\mathrm{s}}^{4}
$$


where $\varepsilon_{\mathrm{w}}$ is water emissivity, $\varepsilon_{\mathrm{w}}=0.96$; $\sigma$ is Stephan's constant, $\sigma=5.67 \times 10^{-8} \mathrm{~W} \mathrm{~m}^{-2} \mathrm{~K}^{-4}$.

Air radiation:

$$
R_{\mathrm{a}, \mathrm{r}}=\gamma \cdot \varepsilon_{\mathrm{a}} \sigma \cdot T_{\mathrm{a}}^{4}\left(1+\kappa \cdot \mathrm{Cc}^{2}\right)
$$

where $\gamma=0.97 ; \varepsilon_{\mathrm{a}}$ is emissivity, $\varepsilon_{\mathrm{a}}=0.937 \times 10^{-5} T_{\mathrm{a}}{ }^{2}$; $\kappa=0.3 ; \mathrm{Cc}$ is cloud coverage $(1 / 10)$.

Evaporation:

$$
C_{\text {evap }}=L\left(T_{\mathrm{s}}\right) \cdot \rho_{\mathrm{a}} \cdot \mathrm{a} \cdot\left(1+U_{\mathrm{w}}\right) \cdot\left[q_{\mathrm{w}}\left(T_{\mathrm{s}}\right)-q_{\mathrm{a}}\right]
$$

where $L\left(T_{s}\right)$ is the latent heat of water vaporization $\left(\mathrm{J} \mathrm{kg}^{-1}\right), L\left(T_{\mathrm{s}}\right)=\left(2500.9-2.36 T_{\mathrm{s}}\right) \times 10^{3} ; \mathrm{a}=0.0015 ; U_{\mathrm{w}}$ is the wind speed $\left(\mathrm{m} \mathrm{s}^{-1}\right) 2 \mathrm{~m}$ above the sea surface; $q_{\mathrm{w}}\left(T_{\mathrm{s}}\right)$ is the specific moisture of saturated air at temperature $T_{\mathrm{s}}\left(\mathrm{kg} \mathrm{kg}^{-1}\right), q_{\mathrm{v}}\left(T_{\mathrm{s}}\right)=0.622 \mathrm{e}\left(T_{\mathrm{s}}\right) /\left[P_{\mathrm{atm}}-0.378 \mathrm{e}\left(T_{\mathrm{s}}\right)\right]$ in which $P_{\text {atm }}$ is the atmospheric pressure at sea surface $(\mathrm{mb})$, and $e\left(T_{\mathrm{s}}\right)=\exp \left[2.302\left(7.5 T_{\mathrm{s}} /\left(237.3+T_{\mathrm{s}}\right)+0.758\right)\right]$ (Magnus Tefen's formula); $q_{\mathrm{a}}$ is the actual specific moisture of air $\left(\mathrm{kg} \mathrm{kg}^{-1}\right)$.

Convection:

$$
C_{\text {conv }}=\rho_{\mathrm{a}} \cdot C_{\text {pa }} \mathrm{a} \cdot\left(1+U_{\mathrm{w}}\right) \cdot\left(T_{\mathrm{s}}-T_{\mathrm{a}}\right)
$$

where $C_{\mathrm{pa}}$ is calorific capacity of air, $C_{\mathrm{pa}}=1002 \mathrm{~J} \mathrm{~kg}^{-1}$ $\left({ }^{\circ} \mathrm{C}\right)^{-1}$

Modelling the horizontal transport. The English Channel is well known for its tide-dominated hydrodynamic regime, associated with current fields which are quasi-homogeneous from surface to bottom. Hence, accurate simulations of instantaneous current fields can be obtained with the help of 2-dimensional horizontal hydrodynamic models (Le Provost \& Fornerino 1985, Salomon \& Breton 1991). However, as far as modelling nutrient cycling in the Channel as a whole is concerned, it seems reasonable to cope with time scales of several days or weeks, that is to say to highlight the long-term drift of water masses and to consider tidal oscillations as dispersive processes. Although some interest has been devoted to this long-term circulation over the last 15 yr (Pingree \& Maddock 1977, 1985, Le Hir et al. 1986, Salomon et al. 1988), a realistic fine mesh map of 2-dimensional tidal residual currents has only recently become available (Salomon \& Breton 1993). Based on average lagrangian drift, the original one-mile-mesh map of residual currents was calculated for a constant tidal coefficient (70), under constant wind forcing (southwesterlies, $6 \mathrm{~m} \mathrm{~s}^{-1}$ )

In order to reduce computation times during the 'exploratory phase' of the ecological model, only a boxmodel approach was retained for simulating the horizontal transport along the Channel. The whole area was split into 71 contiguous boxes (Fig. 1), and the aforementioned residual field then used as the advective background necessary to calculate advective exchanges between these boxes with the help of ELISE software (Ménesguen 1991). ELISE particularly ensures that resulting flow rates through the box system are strictly conservative, by computing minor modifications to the gross advective exchanges deduced from the original lagrangian residual field (for which conservativeness does not constitute a built-in constraint)

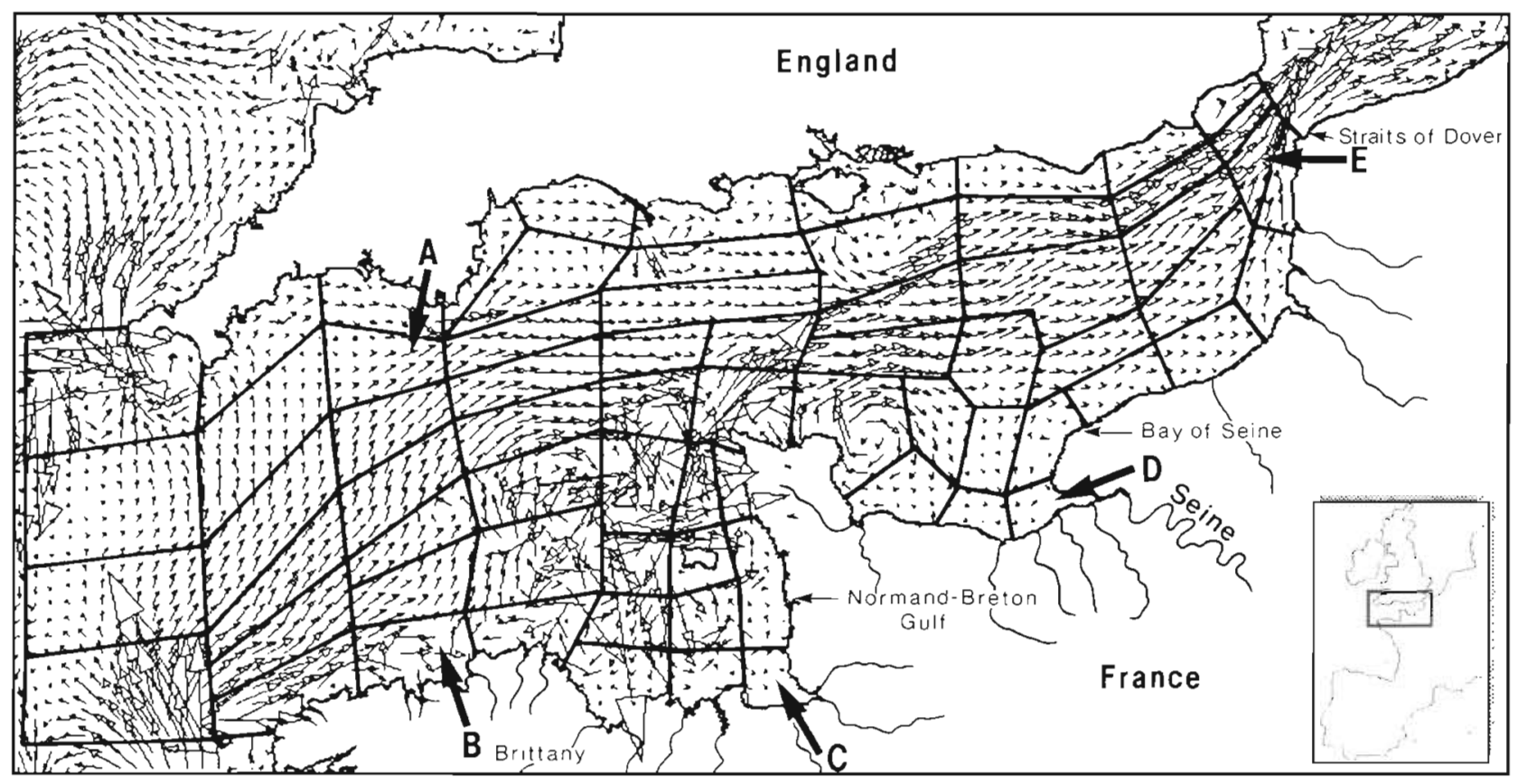

Fig. 1. Map of the Channel with tidal residual flows and contours of the 71 boxes used in the model; capital letters indicate reference boxes used for data vs model comparison 
Under the assumption that horizontal advective flows are proportional to the tidal coefficient, the nominal flow rates between boxes calculated at tidal coefficient 70 were continuously modulated during simulations according to real time-series of the tidal coefficients. Bearing in mind that we are dealing with tide-filtered circulation, i.e without water level oscillations, hence without box volume variation, the general transport equation can then be written as follows:

$$
\begin{aligned}
& V_{1} \cdot \frac{\mathrm{d} X_{i j}}{\mathrm{~d} t}=\sum_{k=1}^{R_{j}} r_{j k} \cdot C_{i k}-p_{j} \cdot X_{i j}+\sum_{k=1}^{N} A_{j k} \cdot\left(\lambda_{k} X_{i k}+\mu_{k} X_{1 j}\right) \\
& \text { Marine inlets - Outlet + Advection between boxes } \\
& -\sum_{k=1}^{N} D_{j k} X_{i j}-X_{i k} \quad-\quad \sum_{i=1}^{S_{l}} E_{j i} \cdot\left(X_{l j}-X_{H j}\right)
\end{aligned}
$$

+ Dispersion within the system + Dispersion with the outside

$+\operatorname{Source}_{j j}\left(X_{j}, p_{1} Y_{j}\right)-\operatorname{Sink}_{i j}\left(X_{, j}, Y_{,}\right)$

where $i$ is state variable index; $j$ is the box index $(N=$ total number of boxes; $V_{j}$ is the volume of box $j_{i} X_{i j}$ is concentration of the variable $i$ in box $j i r_{j k}$ is the flow rate of marine inlet $k$ into box $j\left(R_{j}=\right.$ total number of marine inlets into this box); $C_{i k}$ is the concentration of state variable $i$ in marine inlet $k_{i} p_{j}$ is outlet flow rate out of box $j ; A_{j k}$ is advective flow rate from box $k$ into box $j_{i} \lambda_{k}=1$ and $\mu_{k}=0$ if $A_{j k} \geq 0 ; \lambda_{k}=0$ and $\mu_{k}=1$ if $A_{j k}<0_{i} D_{j k}$ is the eddy dispersive flow rate between box $j$ and $k_{i} E_{j l}$ is the eddy dispersive flow rate between box $j$ and external marine reservoir 1 in contact with this box $\left(S_{j}=\right.$ total number of reservoirs in contact with box $j)_{i} X$, is the vector of state variables within box $j_{i} Y_{j}$ is the vector of external driving variables within box $j_{i} p$ is the vector of biological/ physical parameters.

In this equation, dispersion is treated as a symmetric exchange, between 2 adjacent boxes, of a flow rate $\left(D_{j k}\right)$, which can be estimated according to Eq. (16), in which the horizontal dispersion coefficient $K$ can be expressed as a function of tidal current $\left(U_{C}\right)$ and water depth $(H)$ (Salomon \& Breton 1993)

$$
D_{j k}=K_{j k} \quad S_{j k} / d_{j k}
$$

where $S_{j k}$ is the contact surface between boxes $j$ and $k$ $\left(\mathrm{m}^{2}\right)_{i} d_{j k}$ is the distance between the centres of boxes $j$ and $k(\mathrm{~m}) ; K_{j k}$ is the horizontal dispersion coefficient between boxes $j$ and $k_{1} K_{j k}=k_{\text {disp }} \cdot U_{C} \cdot\left(H_{j}+H_{k}\right) / 2$; $k_{\mathrm{disp}}=7$.

Combining horizontal and vertical models. Whereas Agoumi (1985) and Riou (1990) combined the Niiler \& Kraus (1977) vertical 2-layer model with a classic partial differential equation of horizontal transport, here we linked the vertical 2 -layer model and the horizontal box-model. Each box (i), originally going from surface to bottom, is divided into a surface box (called $i^{\prime}$ ) and a bottom one (called $i^{\prime \prime}$ ). As in the box-models, the topology of exchanges between boxes is defined only by the matrices of flow rates. The original flow rates, such as $A_{1 j}$ (respectively $D_{1 j}$ ), must also be split using the following equations:

$$
\begin{array}{ll}
\text { case } h_{1} \leq h_{j^{\prime}}: & A_{i^{\prime} j^{\prime}}=\left(h_{1} / H \mathrm{C}\right) \cdot A_{i j} \\
& A_{i^{\prime} j^{\prime \prime}}=0 \\
& A_{i^{\prime} j^{\prime}}=\left\{\left[\min \left(H \mathrm{C}, h_{j^{\prime}}\right)-h_{i^{\prime}}\right] / H \mathrm{C}\right\} \cdot A_{i j} \\
& A_{i^{\prime} j^{\prime \prime}}=\left[1-\min \left(H \mathrm{C}, h_{j^{\prime}}\right) / H \mathrm{C}\right] \cdot A_{i j} \\
\text { case } h_{i^{\prime}}>h_{j^{\prime}}: \quad & A_{i^{\prime} j^{\prime}}=\left(h_{j} / H \mathrm{C}\right) \cdot A_{i j} \\
& A_{i^{\prime} j^{\prime \prime}}=\left\{\left[\min \left(H \mathrm{C}, h_{i^{\prime}}\right)-h_{j^{\prime}}\right] / H \mathrm{C}\right\} \cdot A_{i j} \\
& A_{i^{\prime \prime} l^{\prime}}=0 \\
& A_{i^{\prime \prime} j^{\prime \prime}}=\left[1-\min \left(H \mathrm{c}, h_{i}\right) / H \mathrm{C}\right] \cdot A_{i j}
\end{array}
$$

where $H_{1}$ is the total depth of original box $i, H_{j}$ is the total depth of original box $j, H c$ is min $\left(H_{1}, H_{j}\right), h_{1}$. is the thickness of the surface box $i^{\prime}, h_{j^{\prime}}$ is the thickness of the surface box $j$ '.

Although the original total flow rates $A_{i j}$ are conservative, such splitting may introduce non-conservativeness in the resulting surface and bottom compartments, insofar as $H_{3} \neq H_{j}$; a vertical flow rate must then be added between surface and bottom compartments $i$ and $i^{\prime \prime}$ to maintain conservativity

Modelling biogeochemical cycles. Starting with the preliminary nitrogen model of Hoch et al. (1993), a simple model of combined nitrogen and silicon cycles was set up in order to investigate some general features of competition between diatoms (which are silicon- and nitrogen-dependent) and dinoflagellates (which do not require silicon). The 8 following state variables were retained: $X_{1}$, dissolved inorganic nitrogen ( $\left.\mu \mathrm{mol} \mathrm{l^{-1 }} \mathrm{N}\right) ; X_{2}$, dissolved silicon $\left(\mu \mathrm{mol} \mathrm{l}^{-1} \mathrm{Si}\right)_{i}$ $X_{3}$, nitrogen of diatoms ( $\mu$ mol $\mathrm{l}^{-1} \mathrm{~N}$ ) $; X_{4}$, nitrogen of dinoflagellates ( $\mu \mathrm{mol} \mathrm{l}^{-1} \mathrm{~N}$ ); $X_{5}$, detrital organic nitrogen in water $\left(\mu \mathrm{mol} \mathrm{l^{-1 }} N\right) ; X_{6}$, detrital biogenic silicon in water ( $\left.\mu \mathrm{mol} \mathrm{l^{-1 }} \mathrm{Si}\right)_{i} X_{7}$, benthic organic nitrogen $\left(\mu \mathrm{mol} \mathrm{m} \mathrm{m}^{-2} \mathrm{~N}\right) ; X_{8}$, benthic silicon ( $\left.\mu \mathrm{mol} \mathrm{m} \mathrm{m}^{-2} \mathrm{Si}\right)$.

As the aim of this model is to deal with the seasonal time course of phytoplankton over the entire Channel. the transitory buffering effect of internal nutrient storage by phytoplankton ('quota' modelling) was considered as being highly filtered on the seasonal scale and, hence, not taken into account. Phytoplankton growth is then directly dependent on nutrient concentrations in the water, in a classic Michaelis path; diatom growth follows Liebig's minimum law relative to nitrogen and silicon limiting effects. Sea temperature, supplied as a state variable by the thermohaline box-model, acts on biochemical process velocities in a classic exponential manner. Phytoplankton growth is also light-dependent as per Steele's formulation (1962); instantaneous values of photosynthetically active radiations are provided as a driving external variable, equal to one half of the total solar radiation used for the thermohaline model. The light extinction coefficient varies as per 
Riley's formula (1975), which takes into account instantaneous local values of non-chlorophyllous turbidity (fed as an external driving variable) and chlorophyll concentration. According to Antia et al. (1963) and Eppley et al. (1971), the chlorophyll concentration can be deduced from the total nitrogen content of phytoplankton (i.e. $X_{3}+X_{4}$ ) using a ratio $g \mathrm{chl}$ a:mol $\mathrm{N}$ equal to 1 .

As zooplankton and higher trophic levels are not taken into account in this model, neither as a state variable nor as an external driving variable, phytoplankton decay is assumed to be a first order, temperaturedependent process to which a settling process must be added, although only for diatoms. The sedimentation velocity is known to increase in the case of severe nutrient limitation of growth, but validated formulae for this process are lacking. Therefore, an empirical non-linear dependence of sedimentation velocity on nutrient limitation was retained. Microbial biomass was not simulated, but its activity is represented by the first order, temperature-dependent, remineralisation rate of detrital organic nitrogen. Finally, the differential equations representing the local sources and sinks of the 8 biogeochemical state variables can be expressed as follows:

$$
\begin{aligned}
& \frac{\mathrm{d} X_{1}}{\mathrm{~d} t}=r_{\min \mathrm{N}} \cdot f_{T} \cdot X_{S}-\mu_{\max \text { diat }} f_{T} \cdot \min \left(f_{\text {Sidiat }}, f_{\text {Ndıal }}, f_{\text {Ldaat }}\right) \cdot X_{3} \\
& -\mu_{\max \text { dino }} \cdot f_{T} \cdot \min \left(f_{\mathrm{Ndino}}, f_{\mathrm{Ldino}}\right) \cdot X_{4}
\end{aligned}
$$

$\frac{\mathrm{d} X_{6}}{\mathrm{~d} t}=r_{\mathrm{Su} / \mathrm{N}} \cdot m_{\mathrm{dl| \partial t}} \cdot f_{T} \cdot X_{3}+$ bottorn $\cdot \frac{r_{\text {sus }} \cdot X_{8}}{h \cdot 1000}$

$\frac{\mathrm{d} X_{7}}{\mathrm{~d} t}=$ bottom $\cdot\left[\left(v_{\text {suliat }} \cdot X_{3}+v_{\mathrm{sPOM}} \cdot X_{5}\right) \cdot 1000-r_{\text {sus }} \cdot X_{7}\right]$

$\frac{\mathrm{d} X_{8}}{\mathrm{~d} t}=$

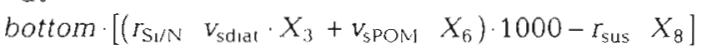

where $h$ is box depth $(\mathrm{m})$; bottom is the boolean indicator bottom $=1$ if the box is in contact with the sediment, 0 elsewhere); $T$ is temperature $\left({ }^{\circ} \mathrm{C}\right)$; diat is diatom; dino is dinoflagellate; for basic parameters see Table 1.

Action of the temperature: $f_{T}=\exp ^{k} T^{T}$

where $k_{T}$ is the coefficient in exponential thermal

effect;
Action of the light: $\quad f_{\mathrm{L}}=\iint\left(\frac{I_{z, \mathrm{t}}}{I_{\text {sal }}}\right) \cdot \exp ^{\left(1-\frac{I_{z, 1}}{I_{\text {sat }}}\right)}$
(Steele's formulation);

Light intensity at depth $z: I_{z, l}=I_{0, l} \cdot \exp ^{-k_{\mathrm{L}} \cdot z}$

Light extinction coefficient (Riley's formula):

$$
k_{\mathrm{L}}=k_{\mathrm{NC}}+0.054 \cdot\left(X_{3}+X_{4}\right)^{2 / 3}+0.0088 \cdot\left(X_{3}+X_{4}\right) \text {. }
$$

where $k_{\mathrm{NC}}$ is the non-chlorophyllous extinction coefficient;

Action of nutrients (Michaelis' formulation)

Nitrogen: $f_{\mathrm{N}}=\frac{X_{1}}{X_{1}+k_{\mathrm{N}}}$ Silicon: $f_{\mathrm{S} 1}=\frac{X_{2}}{X_{2}+k_{\mathrm{Si}}}$

Sedimentation velocity of diatoms: $v_{\text {sdiat }}=v_{\text {sdiatmin }} \cdot$ nutstat $_{\text {diat }}+v_{\text {stiatmax }} \cdot\left(1-\right.$ nutstat $\left._{\text {diat }}\right)$

Effect of nutrient limitation on settling velocity: nutstat $t_{\text {diat }}=\left[\min \left(f_{\text {Ndiat }}, f_{\text {Sidiat }}\right)\right]^{0.2} ;$

Resuspension rate of benthic detrital material: $r_{\text {sus }}=\beta \cdot\left(U_{\mathrm{C}}^{*}\right)^{2}$

An ecological model is a powerful tool to investigate various dynamic properties of the ecosystem. The time-integrated primary production and its comparison to the mean standing crop, the so-called $P: B$ productivity index, is of great interest for ecologists. In our model, yearly gross production per unit of sea surface (P) was computed in each of the 71 boxes, using Eq. (26a) and (26b), dealing respectively with the cases where box $j$ goes from surface to bottom (single layer box-model) or is split by a cline into a surface box $j^{\prime}$ and a bottom one $j^{\prime \prime}$ :

single layer case:

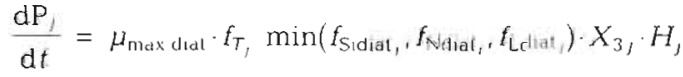

two-layer case:

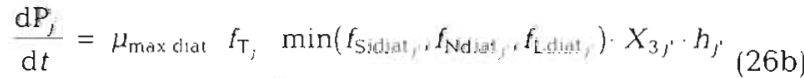

$+\mu_{\text {max diat }} \cdot f_{T_{j}} \cdot \min \left(f_{\text {Sidiat }_{j}}, f_{\mathrm{Nd}_{\text {dial }},}, f_{L_{\text {dilat }}, "}\right) \cdot X_{3 j^{\prime \prime}} \cdot\left(H_{,}-h_{j^{\prime}}\right)$

Another question which frequently arises in ecological problems is the transport of a non-conservative property attached to a basic biogeochemical state variable. For instance, if phytoplankton biomass is this sort of basic state variable, we may be interested in computing the pollutant content changes in this phytoplankton over time and space (expressed in terms of mass of pollutant per phytoplankton biomass unit). But we may also consider some physiological property of the phytoplankton, such as the mean cell size, mean age or mean value of any Michaelis constant, provided 
we are able to write the sink and source terms for this property in each box. The general equation dealing with the transport of a property $(Z)$ attached to the state variable $X$ can be written as follows (notations as in Eq. 15):

$$
\begin{aligned}
& V_{j} \cdot \frac{\mathrm{d}\left(X, Z_{j}\right)}{\mathrm{d} t}= \\
& \sum_{k=1}^{R_{1}} r_{j k} \cdot\left(C_{k} \cdot Z_{k}\right)-p_{1} \cdot\left(X, Z_{1}\right)+\sum_{k=1}^{N} A_{j k} \cdot\left[\lambda_{k} \cdot\left(X_{k} \cdot Z_{k}\right)+\mu_{k} \cdot\left(X, Z_{1}\right)\right]
\end{aligned}
$$

Marine inlets - Outlet + Advection between boxes

$$
-\sum_{k=1}^{N} D_{j k} \cdot\left[\left(X, Z_{j}\right)-\left(X_{k} \cdot Z_{k}\right)\right] \quad-\sum_{l=1}^{S_{l}} E_{j l}\left[\left(X_{j} \cdot Z_{j}\right)-\left(X_{l} Z_{l}\right)\right]
$$

+ Dispersion within the system + Dispersion with the outside

$$
+ \text { Source }_{j}\left(X_{j} \cdot Z_{j}\right)-\operatorname{Sink}_{j}\left(X_{j} \cdot Z_{j}\right)
$$

This equation is similar to the general transport equation of a state variable (Eq. 15) except that the current variable is now the product $X Z$ instead of $X$ alone. In this study, only 3 properties attached to some state variables $\left(X_{3}\right.$, i.e. diatom nitrogen or $X_{1}$, i.e. dissolved inorganic nitrogen) were considered: the mean age of diatoms (source and sink terms of Eq. 27 detailed in Eq. 28), the longitude of the mean 'birth-place' of dissolved inorganic nitrogen (DIN) and the corresponding latitude (source and sink terms of Eq. 27 detailed in Eq. 29): source - sink terms for diatoms age $A$ :

$$
V_{j} \cdot \frac{\mathrm{d}\left(X_{3 j} \cdot A_{j}\right)}{\mathrm{d} t}=V_{j} \cdot X_{3 j}-\left(m_{\mathrm{d} \mathrm{d}_{\mathrm{at}}} \cdot f_{\mathrm{T}_{1}}-\frac{V_{\text {sdiat }_{-}}}{h_{1}}\right) \cdot\left(X_{3,} A_{j}\right)(28)
$$

source - sink terms for DIN 'birth-place' longitude (or latitude) $L$ :

$$
\begin{aligned}
& V_{j} \frac{\mathrm{d}\left(X_{l j} \cdot L_{j}\right)}{\mathrm{d} t}=V_{j} f_{\mathrm{T}}, I_{\mathrm{minN}} \cdot\left(X_{5}, L_{\text {boxcentre }}\right) \\
& -\left(\mu_{\text {max diat }} \cdot \min \left(f_{\text {Sidıat },}, f_{\text {Ndıdt }}, f_{\text {Ldıat }}\right) \cdot X_{3}\right. \text {, } \\
& \left.-\mu_{\max \text { dino }} \cdot \min \left(f_{\mathrm{Ndino}_{1},} f_{\mathrm{Ldino}}\right) \cdot X_{4}\right) \cdot L_{l}
\end{aligned}
$$

Eq. (27) including the source and sink terms detailed in Eq. (29) will provide the centre of gravity for the various origins of the diatoms actually present in box $j$, based on the hypothesis that the geographic origin of diatoms newly produced in box $j$ is the centre of this box.

Data used for the model. Parameter values: Because of the extreme roughness of our mathematical description compared to the complexity of the real ecosystem, precise values resulting from experimental work done on well-defined subsystems can only be used as guidelines for the values effectively used in the model. Table 1 gives the parameter values used in this model, with the corresponding references from the literature.

Boundary conditions: The main 31 rivers flowing into the Channel were taken into account as separate inlets (see Eq. 15), and the western input of Atlantic

\begin{tabular}{|c|c|c|c|c|}
\hline Symbol & Definition & Unit & Value & Source \\
\hline$k_{\mathrm{T}}$ & Coefficient in exponential thermal effect & $\left({ }^{\circ} \mathrm{C}\right)^{-1}$ & 0.07 & Baretta-Bekker et al. (1994) \\
\hline \multicolumn{5}{|c|}{ Diatom parameters } \\
\hline$\mu_{\text {maxdiai }}$ & Maximum growth rate at $0^{\circ} \mathrm{C}$ & $d^{-1}$ & 0.7 & Paasche (1973) \\
\hline$I_{\text {satdiat }}$ & Optimal light intensity & $\mathrm{W} \mathrm{m}^{-2}$ & 70 & Mortain-Bertrand et al. (1988) \\
\hline$k_{\text {Nảiat }}$ & Halt-saturation constant for inorganic nitrogen & $\mu \mathrm{mol} \mathrm{I}^{-1}$ & 2 & Eppley et al. (1969) \\
\hline$k_{\text {Sidiat }}$ & Half-saturation constant for dissolved silica & $\mu \mathrm{mol} \mathrm{l}{ }^{-1}$ & 1 & Paasche (1973) \\
\hline$r_{\mathrm{Sl} / \mathrm{N}}$ & Si:N ratio & $\mathrm{mol} \mathrm{mol}{ }^{-1}$ & 0.5 & Harrison et al. (1977) \\
\hline$m_{\text {d:at }}$ & Mortality rate at $0^{\circ} \mathrm{C}$ & $d^{-1}$ & 0.03 & Ross et al. (1993) \\
\hline$V_{\text {sdiatmin }}$ & Minimal sedimentation velocity of diatoms & $m d^{-1}$ & 0.5 & Smayda $(1970)$ \\
\hline$V_{\text {schatmax }}$ & Maximal sedimentation velocity of diatoms & $\mathrm{m} \mathrm{d}^{-1}$ & 2 & Smayda $(1970)$ \\
\hline \multicolumn{5}{|c|}{ Dinoflagellate parameters } \\
\hline$\mu_{\operatorname{maxd} i n o}$ & Maximum growth rate at $0^{\circ} \mathrm{C}$ & $d^{-1}$ & 0.3 & Morgan \& Kalff (1979) \\
\hline$I_{\text {Satdino }}$ & Optimal light intensity & $W \mathrm{~m}^{-2}$ & 110 & Ryther (1956) \\
\hline$k_{\text {ivdino }}$ & Half-saturation constant for inorganic nitrogen & $\mu \mathrm{mol} \mathrm{l}^{-1}$ & 3.8 & Eppley et al. (1969) \\
\hline$m_{\text {dino }}$ & Mortality rate at $0^{\circ} \mathrm{C}$ & $\mathrm{d}^{-1}$ & 0.02 & Calibration \\
\hline \multicolumn{5}{|c|}{ Organic matter parameters } \\
\hline$V_{\text {SPOM }}$ & Sedimentation velocity of organic matter & $\mathrm{m} \mathrm{d}^{-1}$ & 1 & Bienfang (1980) \\
\hline$\beta$ & Coefficient for resuspension rate & $m^{-2} s^{2}$ & 30 & Calibration \\
\hline$r_{\operatorname{minn}}$ & Mineralization rate of detrital nitrogen at $0^{\circ} \mathrm{C}$ & $d^{-1}$ & 0.04 & Vinogradov et al. (1973) \\
\hline$r_{\text {diss }}$ & Dissolution rate of biogenic silicon at $0^{\circ} \mathrm{C}$ & $d^{-1}$ & 0.05 & Kamatani (1971) \\
\hline
\end{tabular}
water as the $32 \mathrm{nd}$ inlet. No external dispersive source was considered. Obviously, among the rivers, the river Seine plays a major role in nutrient supply, because its catchment area represents $2 / 3$ of the total catchment areas surrounding the Channel (Taylor et al. 1981) and $40 \%$ of the economic activity and $30 \%$ of the popula-

Table 1. Parameters used in the formulation of biological/chemical processes 
tion of France are concentrated in this area (Goujon et al. 1992). 1980 was chosen as a reference year, due to the relative abundance of various data available. Rivers were considered as importing only dissolved inorganic nitrogen and silicon, temperature and salinity (zero value). For the river seine only, detrital organic nitrogen concentrations were also estimated as Kjeldahl nitrogen minus DIN. Monthly synchronous measured flow rates and concentrations were used when available. Otherwise, only multi-annual average concentrations were used. For the river Seine alone, fortnightly values were generally used, except during flooding periods, where values were fed in every $2 \mathrm{~d}$ At the western oceanic boundary, sea surface temperature during 1980 was provided by Meteo-France (SSTGASC data base); the sea bottom temperature was deduced before Day 120 and after Day 288 from the fact that bottom and surface temperatures were identical, whereas between these 2 dates, due to the existence of a thermocline, the bottom temperature was obtained by linear interpolation between the values on Days 120 and 288. The salinity of Atlantic water was set at $35.3 \%$ over the entire year. The only available data on concentrations of inorganic nutrient, diatom and dinoflagellate concentrations in Atlantic water were measured by Morin et al. (1991) and L'Helguen (1991) during 1982 and 1986 respectively, but can be considered as a good boundary condition for 1980, considering the high stability of the oceanic pelagic system

As far as initial values of state variables are concerned, accuracy is unnecessary, because the model is run until a yearly periodicity is reached.

Driving variables: The non-chlorophyllous extinction coefficient $k_{\mathrm{NC}}$ was imposed as a set of values varying over time and space. Over the entire Channel, $k_{\mathrm{NC}}$ varied sinusoidally between a local minimum value (on July 1) and a local maximum value (on January 1). Local extreme values were higher in coastal boxes (0.1 to $0.4 \mathrm{~m}^{-1}$ along the coast of the Normand-Breton Gulf, 0.4 to $1.0 \mathrm{~m}^{-1}$ off the Seine estuary) than in the middle part of the Channel $\left(0.05\right.$ to $\left.0.2 \mathrm{~m}^{-1}\right)$.

Meteorological forcing for the year 1980 was based on daily average measurements at the La Hague station (northwest cape of Cotentin peninsula, mid-Channel), and were provided by Meteo-France. Meteorological variables necessary for thermocline (and photosynthesis) modelling include insolation duration $\left(\mathrm{h} \mathrm{d}^{-1}\right)$, wind speed $\left(\mathrm{m} \mathrm{s}^{-1}\right)$, air temperature $\left({ }^{\circ} \mathrm{C}\right)$, air moisture $(\%)$, atmospheric pressure (mbar) and cloud cover $\left(10^{-1}\right)$. Instantaneous solar irradiance was calculated from astronomic considerations (Milankovitch 1930), corrected for cloudiness as per Brock (1981).

Calibration data: In contrast with the North Sea, measurements in the English Channel corresponding to the main biogeochemical state variables of the model are scarce, even for 1980. In order to cover the various features of the Channel ecosystem dynamics, 5 boxes (see Fig. 1) were selected to assess the model, 4 of them showing available in situ measurements: (1) an early stratified zone of the central western Channel (box A, depth $=77 \mathrm{~m}$ ), with data collected in 1975 and 1976 by Pingree et al. (1977) and Holligan \& Harbour (1977) respectively, (2) a deep coastal frontal zone in the western Channel, on the French side (box B, depth $=65 \mathrm{~m}$ ). (3) a shallow coastal area of the NormandBreton Gulf (box C, depth $=18 \mathrm{~m}$ ), with data from Le Hir et al. (1986), (4) the box of the Seine estuary (box D, depth $=18 \mathrm{~m}$ ), with data compiled from the R.N.O. (Réseau National d'Observation de la qualité du milieu marin) data base, including the year 1980, (5) a central zone of the Straits of Dover (box E, depth $=45 \mathrm{~m}$ ), with measurements from Bentley (1984).

\section{RESULTS}

\section{Thermohaline stratification at various fixed locations}

Fig. 2 shows the seasonal course of sea surface and bottom temperatures in the 5 previously defined boxes and Fig. 3 gives the corresponding thickness of the surface layer. Three main patterns in the water column can be distinguished: in summer, a well-established thermal stratification in the northwestern part (box A: calculated bottom-surface $\Delta \sigma$ annual maximum $=0.98$, annual mean $=0.31$ ); a permanent, mostly haline stratification in the Seine plume (box D: calculated bottom-surface $\Delta \sigma$ annual maximum $=5.75$, annual mean = 2.87); and a permanent vertical mixing, with possible weak, transient stratification episodes (boxes $C$ and $E$ : calculated bottom-surface $\Delta \sigma$ annual maximum $=0.5$, annual mean $=0.03$ ). Due to its position on the summer tidal front between stratified and mixed waters, box $B$ (calculated bottom-surface $\Delta \sigma$ annual maximum = 1.09 , annual mean $=0.26$ ) exhibits a transitional characteristic, with alternating episodes of thermal stratification (during neap tides) and partial mixing (during high tides). Comparison with existing data supports the idea that a simple 2-layer model is able to account for the main features of the thermohaline budget of shelf waters: buffered seasonal variations ( 8 to $16^{\circ} \mathrm{C}$ ) but strong summer stratification in deeper waters (ca $100 \mathrm{~m}$ ); quasi-permanent mixing in shallow waters and seasonal thermal amplitude which increases with the shallowness of the water; and permanent stratification in plumes of large rivers, with surface waters exhibiting enlarged seasonal thermal amplitude due to mixing with thermally less-buffered freshwater. In box $D$, the winter temperature inversion allowed by 

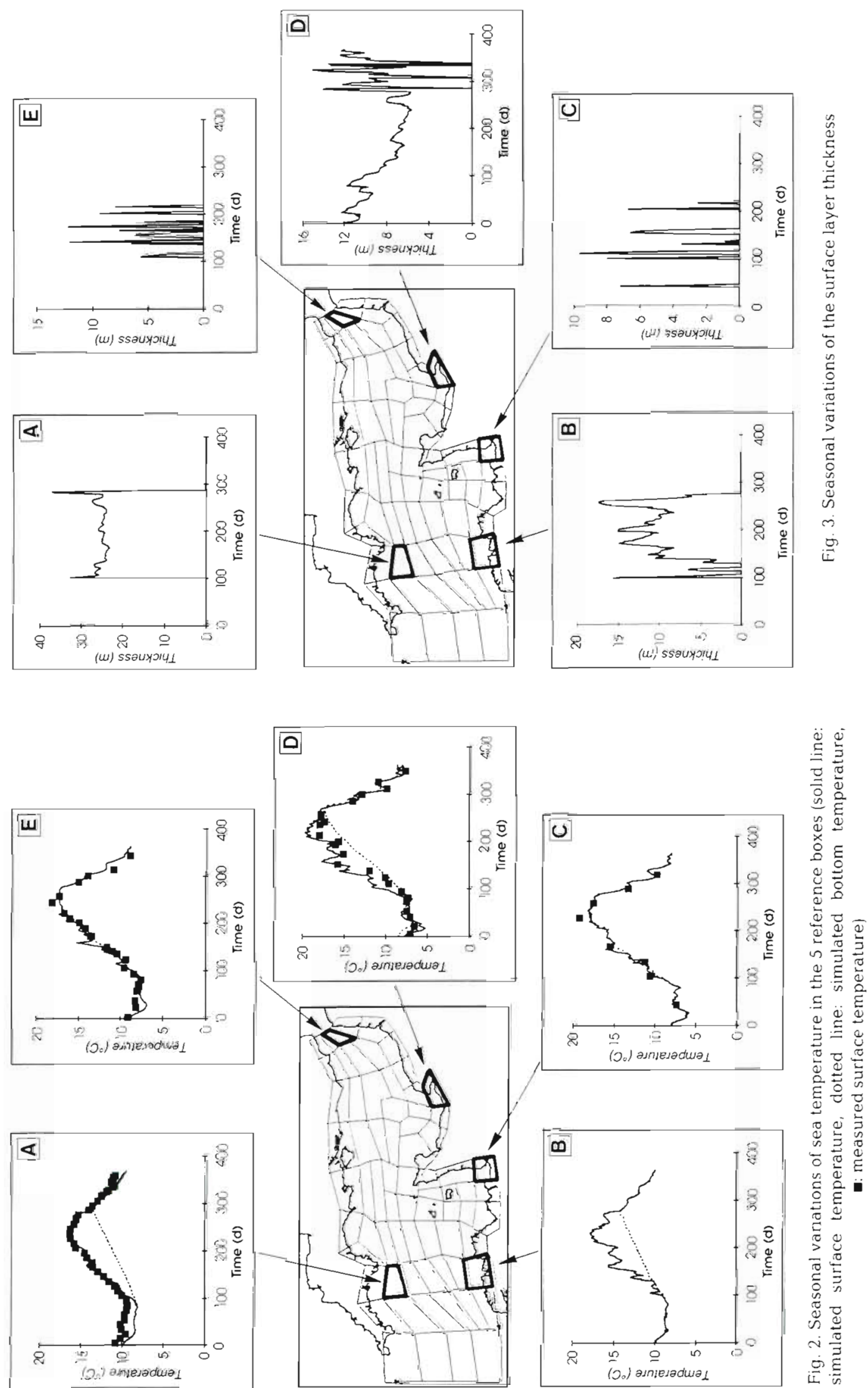
the strength of the haline component of buoyancy should be noted. In mid-January, the simulated surface temperature is about $6^{\circ} \mathrm{C}$, whereas the bottom temperature is still about $8^{\circ} \mathrm{C}$. With regard to the thickness of the surface layer in well-stratified regions, the simulated value in box A ( $25 \mathrm{~m}$ ) correlates well with current observations at International Hydrographic Station $\mathrm{E}_{1}\left(50^{\circ} 02^{\prime} \mathrm{N}, 4^{\circ} 22^{\prime} \mathrm{W}\right)$, showing the thermocline around $20 \mathrm{~m}$ (Armstrong \& Butler 1968). In the Seine plume region, the lack of spatial resolution of our boxmodel precludes any valuable comparison with point measurements. These are highly dependent on the sampling localisation in space and time along the strong dilution gradient and in the tidal period.

\section{Biogeochemical seasonal pattern at various fixed locations}

Figs. 4 to 7 show the periodic seasonal time-course obtained in the 5 previously defined boxes for total inorganic nitrogen, dissolved silica, total chlorophyll and age of diatoms, respectively. In order to visualise the effect of stratification, the simulation obtained without any stratification (i.e. with 1-layer boxes which are well-mixed from surface to bottom) has been drawn on the same figure, along with the simulation(s) whose thermal or haline stratification exhibits the greatest difference with the former.

Generally speaking, DIN show a similar seasonal pattern all over the Channel, i.e. the well-known sharp decrease of concentrations during the first spring phytoplanktonic bloom, followed by a low concentration phase until the beginning of autumn, when an uptake decrease and benthic resuspension allow a gradual replenishment of dissolved inorganic stocks until the end of winter. Two peculiarities should be noted, however

(1) Winter maximum levels in boxes A and B, receiving quasi-unchanged Atlantic water $\left(\sim 7 \mu \mathrm{mol} \mathrm{l^{-1 }} \mathrm{N}\right.$, $4 \mu \mathrm{mol} \mathrm{l^{-1 }} \mathrm{Si}$ are lower than in coastal boxes $\mathrm{C}$ $\left(13 \mu \mathrm{mol} \mathrm{l} \mathrm{l}^{-1} \mathrm{~N}, 7 \mu \mathrm{mol} \mathrm{l^{-1 }} \mathrm{Si}\right)$ and $\mathrm{D}\left(100 \mu \mathrm{mol} \mathrm{l^{-1 }} \mathrm{N}\right.$, $40 \mathrm{mmol}^{-1} \mathrm{Si}$ in surface layer) experiencing terrestrial loadings. In the latter case, the Seine nutrient loadings are mainly confined to the surface layer above the halocline, leading to high winter concentrations which are better simulated by a haline or thermohaline model than by a 1-layer model.

(2) Simulated summer low levels in surface waters are lower for nitrogen $\left(<0.5 \mu \mathrm{mol} \mathrm{l^{-1 }} \mathrm{N}\right)$ than for silica $\left(\sim 1 \mu \mathrm{mol} \mathrm{l}^{-1}\right.$ Si) everywhere, except in the Seine plume (box D) where simulated dissolved silica disappears from Day 120 until Day 280, whereas DIN slowly drops from $35 \mu \mathrm{mol} \mathrm{l}^{-1} \mathrm{~N}$ on Day 120 to nearly 0 on Day 250. The model behaviour is then favourable for a summer nitrogen limitation of phytoplanktonic growth all over the Channel, except in the coastal zone receiving the Seine plume, which might be silica-limited. Concentration data presented in Figs. $4 \& 5$ are not inconsistent with nitrogen limitation in boxes $A$ and $E$, whereas no nutrient limitation appears in box D: DIN remains above $20 \mu \mathrm{mol} \mathrm{l}^{-1} \mathrm{~N}$ and dissolved silica above $5 \mu \mathrm{mol} \mathrm{l^{-1 }}$ Si all summer long. Obviously, the model, whether stratified or not, overestimates the biological utilisation of nutrients off the Seine estuary. Underestimation of simulated nutrient concentrations in boxes $\mathrm{C}$ and $\mathrm{E}$ lasts from early summer until the end of autumn.

The simulated total chlorophyll concentration also shows a classic temperate, oligotrophic open sea seasonal course, except in the Seine plume, where high nutrient inputs create a typical eutrophic situation. The oligotrophic (boxes A and B) or mesotrophic types (boxes $C$ and $E$ ) are characterised by low chlorophyll concentrations during winter, an initial intense phytoplanktonic bloom, mainly composed of diatoms, in April or May, followed by rather low values all summer long, and ending in autumn with a second, smaller bloom. The spring bloom height, when expressed in the same unit as the limiting nutrient, in this case nitrogen, is about half of the winter nutrient concentration preceding the bloom. In eutrophic areas (box D), the seasonal pattern is quite different: continuous nutrient inputs over the entire year, although less abundant in summer, promote a strong summer phytoplanktonic bloom which is higher than those in spring and autumn. Whatever its location and its origin, the stratification makes the spring bloom come earlier and sharper (boxes A and D). As noted for nutrients, some local peculiarities appear:

(1) With respect to the summer phytoplankton biomass, thermal stratification in the open sea (in this case, the western Channel) plays an almost-opposite role to haline (or thermohaline) stratification in estuarine zones. Whereas the thermocline prevents nutrients in the bottom layer from feeding phytoplankton in the surface layer of the open sea, leading to a decrease of simulated summer biomass from a 1-layer model to a thermally stratified one (box A), the coastal halocline maintains the terrestrial nutrients and the marine phytoplankton which feed on them in a thin surface layer. This prevents their immediate dilution in the whole water column and enhances spring and summer blooms (box D). Of particular interest are the areas of intermittent stratification in spring and summer, such as the boxes situated along the frontal zone between the well-stratified western Channel and the wellmixed mid-Channel. Box B, for instance, shows oscillations of summer phytoplankton biomass in surface waters corresponding to periods of thermal stratifi- 

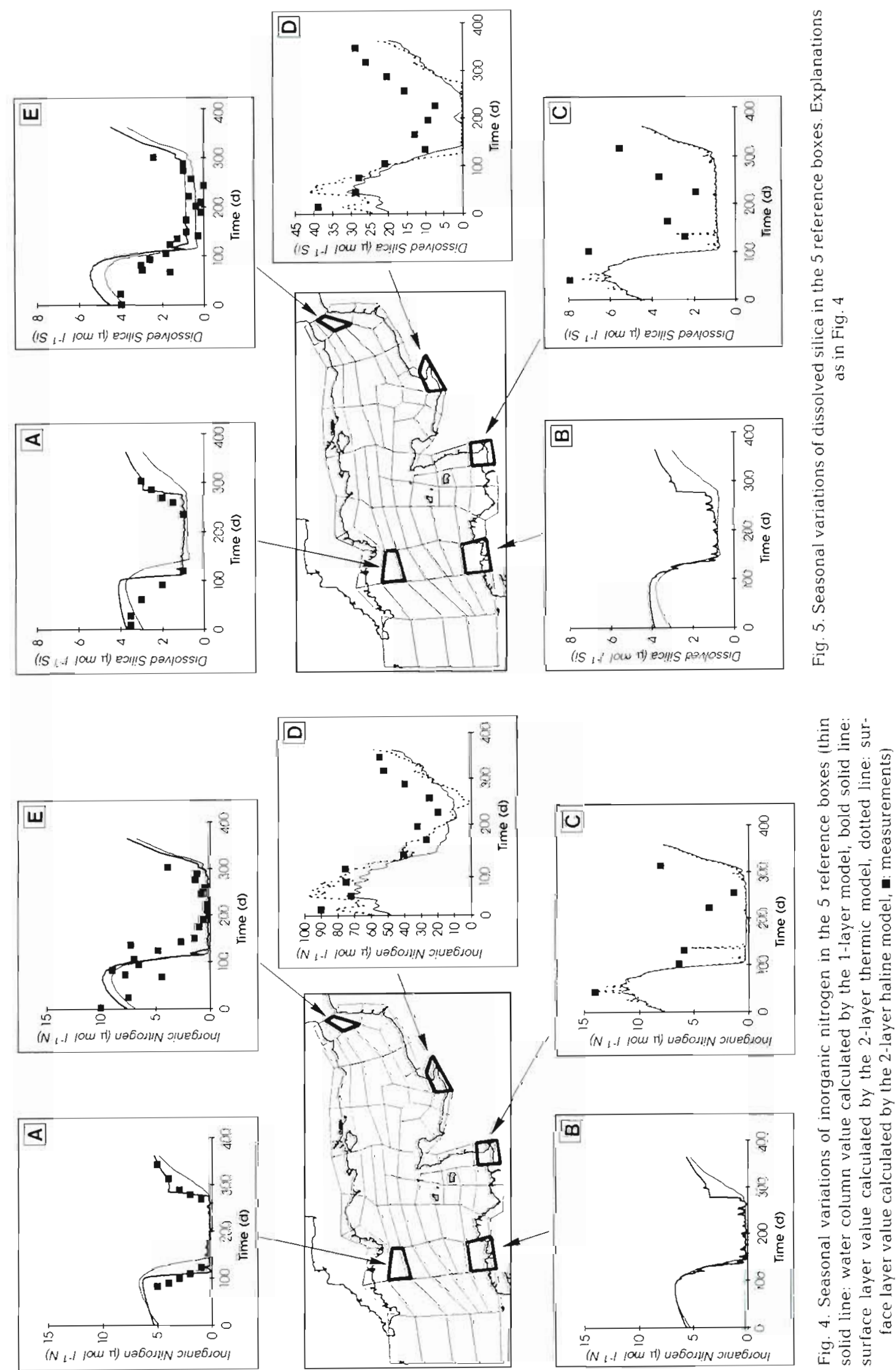

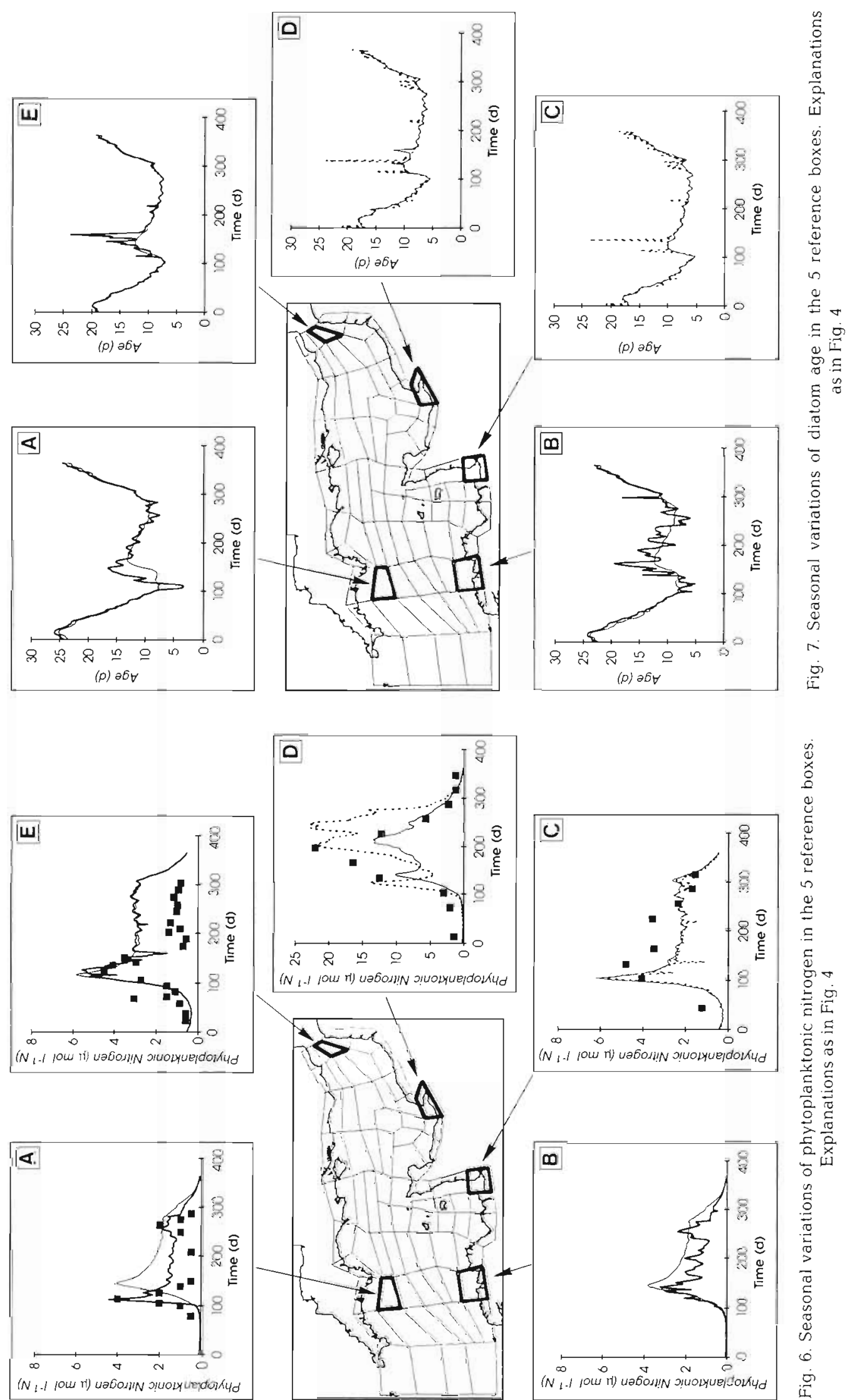

年

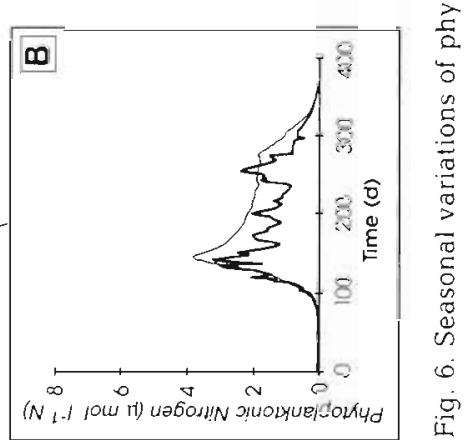


cation (biomass minima) alternating with periods of partial mixing (biomass maxima).

(2) In the western Channel (box A) and in the Straits of Dover (box E), the simulated total summer phytoplankton nitrogen is about 3 times the observed values. This discrepancy is mainly due in the model to diatoms. It may be caused, in box A only, by an excessive growth rate, related for instance to excessive silica concentrations, but also by insufficient mortality. The relatively good correlation between simulated nutrient concentrations and data in box A may indicate that an inappropriate formulation of diatom mortality should be corrected first. Unfortunately, the lack of zooplankton data in this model does not allow any evaluation of the grazing pressure on diatoms. In box E, the excess of phytoplankton in summer may be caused by excessive dispersion of the enriched French coastal waters towards the middle of the channel off the Straits of Dover; this artefact is due to the large box size and to the isotropic formulation taken for dispersion (Eq. 16), which obviously overestimates dispersion across the stream lines

The calculated mean age of diatoms (Fig. 7) shows the same pattern all over the Channel: highest values are to be found in January, from which a quasi-constant decrease leads to the annual minimum which corresponds exactly to the spring bloom peak. Another sudden increase in age takes place during spring bloom decay, but the age drops again over the summer. As mean age decrease is caused either by 'fresh' $\mathrm{di}$ atoms entering through the Atlantic inflow, or by the creation of 'new' diatoms through primary production in the Channel, examination of the age time course, in boxes C, D and E especially, sufficiently far away from the western Atlantic input to avoid influence by the 'fresh' diatoms input, may bring us to the following considerations:

(1) The autumnal senescent phase does not continue during the winter. This indicates that, as early as mid-January, growth processes surpass death processes, inducing a continuous rejuvenation of diatoms. This result is not apparent when looking only at the diatom biomass time course, which shows a sharp increase only in the terminal phase of positive net growth, i.e. in the spring bloom exponential phase. The age variable then appears to be more sensitive to net growth rate than the biomass variable, and could probably be more related to productivity than to production rates

(2) The winter age maximum is higher in deep waters ( $26 \mathrm{~d}$ in box A, $24 \mathrm{~d}$ in box B, $20 \mathrm{~d}$ in box E) than in shallow, coastal ones ( $17 \mathrm{~d}$ in boxes $\mathrm{C}$ and $\mathrm{D}$ ), in relation with the stronger light limitation in deep water columns, which delays 'new' diatom production.

\section{Spatial heterogeneity of global indicators}

Ecologists commonly use integrated production and productivity indexes as useful tools for a synthetic appraisal of how the ecosystem functions at the primary producer level. Here, we present some results obtained for diatoms, those for dinoflagellates are presented in the companion paper (Hoch \& Ménesguen 1996) on sensitivity analysis.

The contribution of various areas in the Channel to the total annual phytoplanktonic production of this epicontinental sea may be obtained by mapping the annual water-column integrated, gross primary production per sea surface unit. Fig. 8 a shows the result
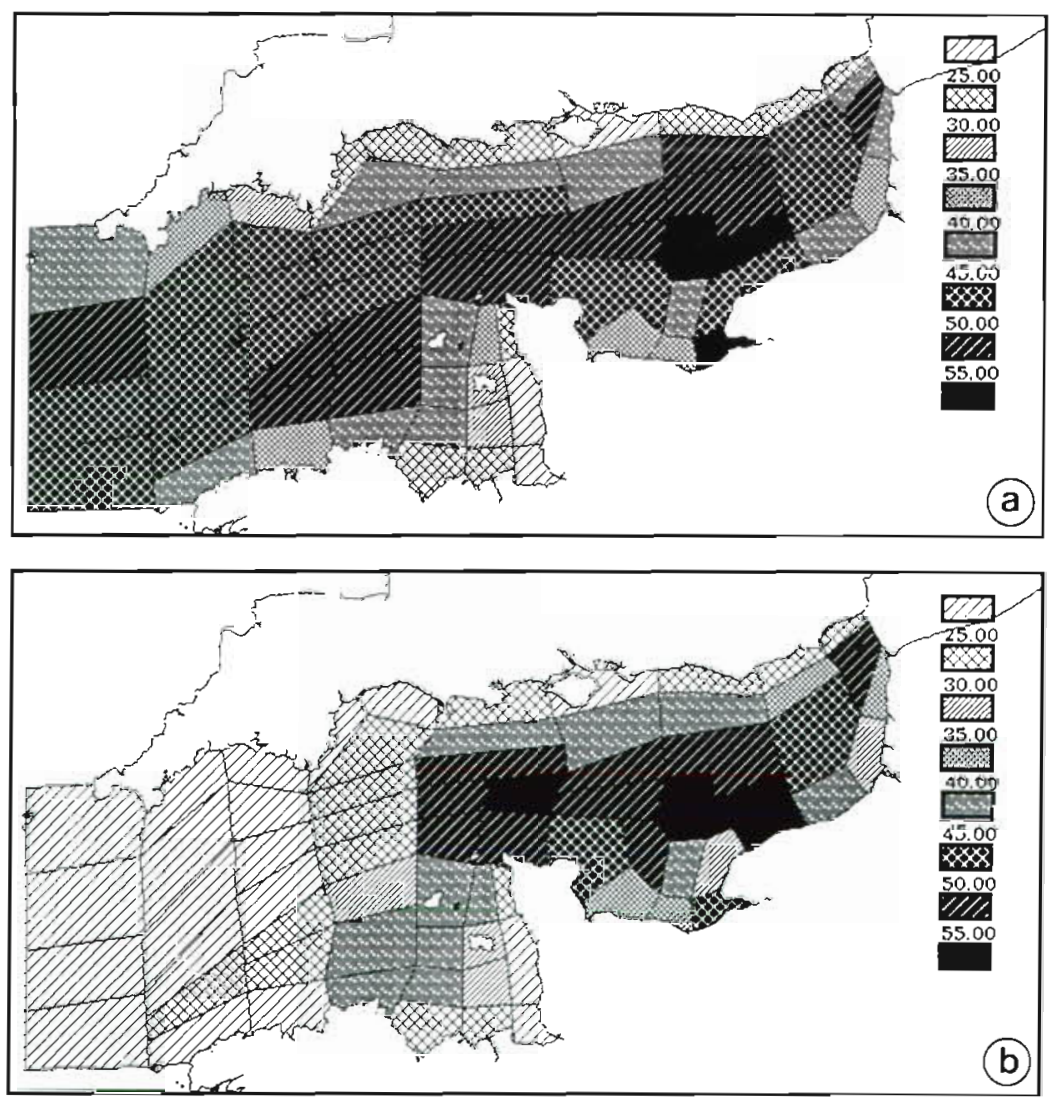

Fig. 8. Map of nitrogen annually incorporated in gross primary production ( $\mathrm{g} \mathrm{m}^{-2}$ $\mathrm{yr}^{-1}$ ), calculated with the (a) 1-layer model and with the (b) 2 -layer thermohaline model 
obtained using the 1-layer model, whereas Fig. 8b shows the map provided by the 2 -layer thermohaline model. The most striking feature is the drastic drop in primary production in the western Channel when the spring-summer thermal stratification is taken into account, from about 45 to $50 \mathrm{~g} \mathrm{~m}^{-2} \mathrm{yr}^{-1} \mathrm{~N}$ in the 1 -layer model down to 20 to $25 \mathrm{~g} \mathrm{~m}^{-2} \mathrm{yr}^{-1} \mathrm{~N}$ in the stratified one. The same effect, but to a considerably lower extent in space, can be observed along the Seine plume in the eastern Channel. This negative influence of stratification on the biological production of the water column can be explained by the fact that nutrients produced by remineralisation of detrital material settled into the bottom layer are trapped there by the pycnocline. The second characteristic of annual depth-integrated values of gross primary production is the higher values found for deep, well-mixed waters than for coastal waters, excepting the Seine plume. This indicates that, in spite of their higher nutritive potentialities, coastal waters are too turbid and too shallow to support a very high production per surface unit; deeper water columns, if wellmixed and transparent enough to have a compensation point near the bottom, are more productive per surface unit, even though their phytoplankton concentration remains relatively low. Compare, for instance, the boxes in the deep middle zone of the eastern Channel (depth $-70 \mathrm{~m}$, production $>50 \mathrm{~g} \mathrm{~m}^{-2} \mathrm{yr}^{-1} \mathrm{~N}$ ) and the shallow boxes in the Normand-Breton Gulf (depth $\sim 25 \mathrm{~m}$, production $<25 \mathrm{~g} \mathrm{~m}^{-2} \mathrm{yr}^{-1} \mathrm{~N}$ ).

When mapping diatom productivity values (Fig. 9), i.e. the $P: B$ ratio of the above-mentioned production $P$ to the mean annual biomass $B$ found in the total water column under a sea surface unit, the picture is com- pletely different, nearly opposite. Coastal boxes, especially in the eastern Channel and the Normand-Breton Gulf, are the most efficient, whereas deep, well-mixed areas show lower $P: B$ values. The behaviour found in the Normand-Breton Gulf seems particularly interesting. There, very high productivity is combined with low production per surface unit. Summer stratified areas of the western Channel, however, exhibit the lowest productivity values, as they did for production values.

An unusual look at the global working of the Channel ecosystem may be gained from mapping the annual trajectory followed by the mean 'birth-place' of some biogeochemical state variables. Fig. 10 shows the trajectories obtained for DIN present in the 5 reference boxes. Box D, just off the Seine estuary, differs from the 4 other boxes by the fact that all year long, the DIN originates from the region of box $\mathrm{D}$, either coming from the Seine loading or from remineralisation in the box itself. Four other boxes exhibit more or less the same pattern, i.e. during late spring and summer, DIN observed in the box originates from the box itself or its vicinity, because of intensive turnover caused by active uptake and remineralisation, whereas during late autumn and winter, DIN tends to come from the main 'fresh' DIN source, i.e. the Atlantic Ocean, because of the low biological utilisation during the eastward drift of water masses.

\section{DISCUSSION}

The ecological model presented here is a compromise between the wish to model a rather wide area on a multi-

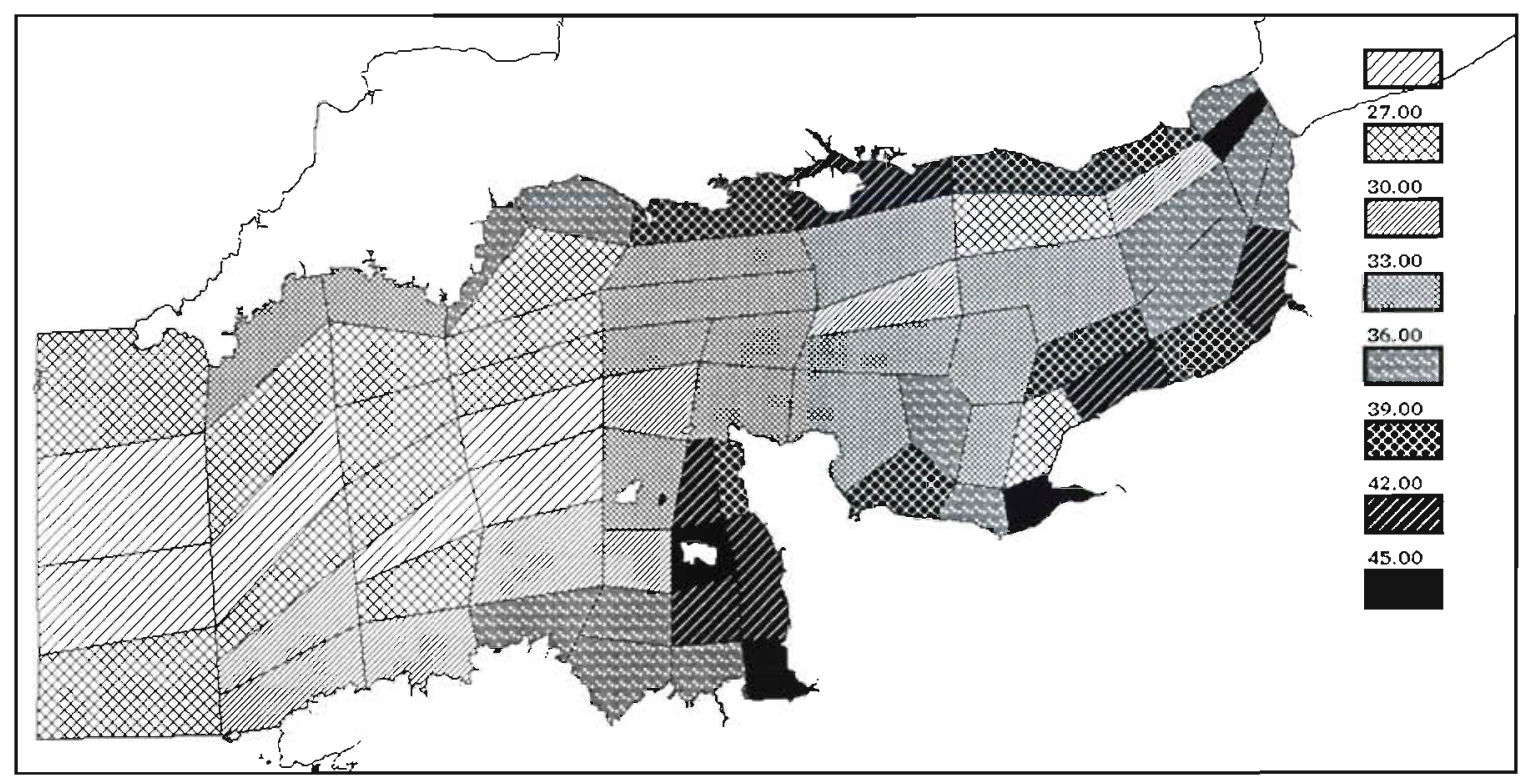

Fig. 9. Map of diatom annual productivity $\left(\mathrm{yr}^{-1}\right)$ calculated with the 2-layer thermohaline model 


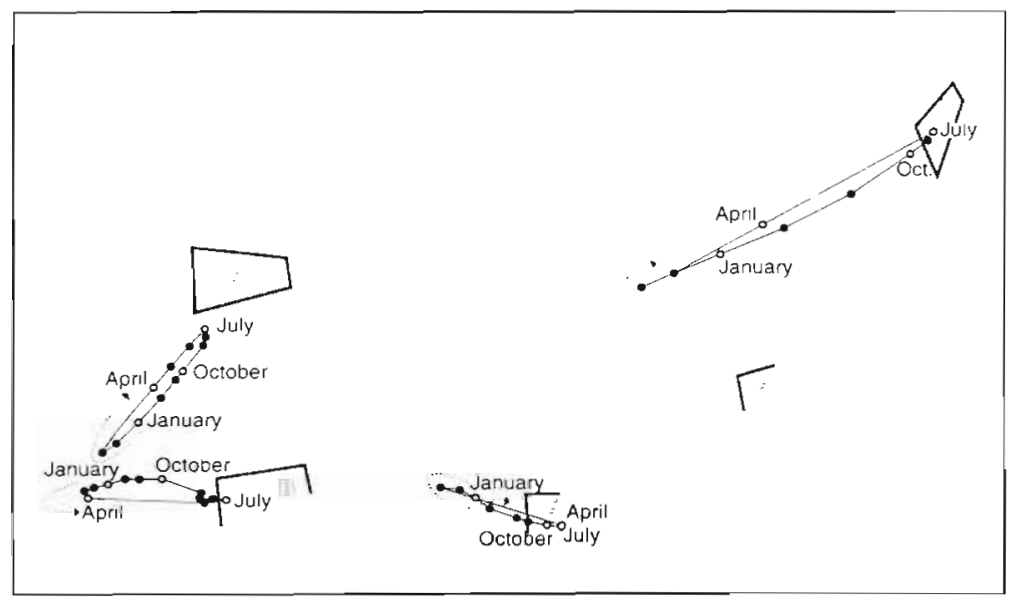

Fig. 10. Annual trajectories followed by the mean 'birth-place' of DIN located in the 5 reference boxes. ( Position of the mean 'birth-place' at the beginning of each month (some may be superimposed); (아 the 4 months January, April, July and October

annual basis, and the necessity of maintaining acceptable computing requirements. The large horizontal size of each box may blur local structures, partly because physical or ecological characteristics may have been averaged over a too large, non-homogeneous zone, partly because compartmental formulation of transport (Eq. 15) creates numerical diffusion. This is all the more true as the mean residence time in a box is relatively long with respect to the integration time step. These artefacts may be particularly prominent in areas of strong natural horizontal gradients, as frontal zones or very coastal areas with important river discharges (e.g. box D including the Seine plume). Horizontal averaging may also alter the behaviour of the vertical component of the model, since the box includes areas with very different depths. This is especially the case here for coastal boxes along the Brittany coast, such as box $B$. With a mean depth of $65 \mathrm{~m}$, this box is deep enough to be temporarily thermally stratified in the model, whereas in this region, the coastal strip within the $50 \mathrm{~m}$ isobath is well known to be mixed all year long (L'Helguen 1991). More accurate evaluation of primary production in these areas of strong bathymetric or hydrological gradients would obviously require a finer spatial resolution.

As far as annual primary production is concerned, few measured values are available for the English Channel. For the year 1979 at a near-coastal station of the Bay of Morlaix, Brittany, France (located in our box B), with a depth of about $40 \mathrm{~m}$ and hence permanently mixed, Wafar (1981) gives a total gross primary production value amounting to $314 \mathrm{~g} \mathrm{C} \mathrm{m}^{-2}$, for a mean annual biomass of $1.16 \mathrm{mg} \mathrm{chl} \mathrm{a} \mathrm{m}^{-3}$. At the same station for the year 1988 , L'Helguen (1991) gives an annual gross production of $63.2 \mathrm{~g} \mathrm{~N} \mathrm{~m}^{-2}$, obtained by the ${ }^{15} \mathrm{~N}$ incubation technique. In the stratified western part of the Channel, Boalch (1987) gives daily gross production values, averaged monthly over the period 1964-1974, with or without exceptional values from 1966. When integrated over the whole year, these data yield a mean annual gross production of about $155 \mathrm{~g} \mathrm{C} \mathrm{m}^{-2}$ at Stn $E_{1}$ (in our box A), greater than $155 \mathrm{~g} \mathrm{C} \mathrm{m}^{-2}$ at $\operatorname{Stn} E_{2}$ $\left(49^{\circ} 28^{\prime} \mathrm{N}, 4^{\circ} 41^{\prime} \mathrm{W}\right.$ ) and greater than $113 \mathrm{~g} \mathrm{C} \mathrm{m}^{-2}$ at Stn $\mathrm{E}_{3}\left(49^{\circ} 35^{\prime} \mathrm{N}, 5^{\circ} 52^{\prime} \mathrm{W}\right.$ ) (daily production during August is lacking for both these stations). Finally, in the French coastal strip of the Straits of Dover, in a $30 \mathrm{~m}$ deep, permanently mixed station, Quisthoudt (1987) measured an annual gross primary production amounting to $336 \mathrm{~g} \mathrm{C} \mathrm{m}^{-2}$ Comparison with our computed values requires choosing a mean value for the phytoplanktonic C:N ratio by mass: the Redfield ratio, i.e. $(106 \times$ $12) /(16 \times 14)=5.68$ may be used.

For annual $P: B$ estimates, no value can be found in the literature ${ }_{i}$ however, the fact that shallow coastal areas exhibit greater productivity than deeper, stratified areas has also been noted by Prestidge \& Taylor (1995) as a result of their Irish Sea model. Only rough evaluations can be derived from data supplied by some

Table 2. Comparison between measured and calculated annual gross primary production and productivity in some places in the Channel or the North Sea

\begin{tabular}{|c|c|c|c|c|c|c|c|}
\hline Location & $\begin{array}{l}\text { Depth } \\
(\mathrm{m})\end{array}$ & $\begin{array}{l}\text { Mean annual } \\
\text { biomass } \\
\left(\mathrm{mg} \mathrm{m}^{-3} \mathrm{chl} \text { a) }\right.\end{array}$ & 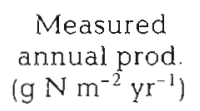 & $\begin{array}{c}\text { Simulated } \\
\text { annual prod. } \\
\left(\mathrm{g} \mathrm{N} \mathrm{m} \mathrm{N}^{-2} \mathrm{yr}^{-1}\right)\end{array}$ & $\begin{array}{c}\text { Measured } \\
P: B \\
\left(\mathrm{Yr}^{-1}\right)\end{array}$ & $\begin{array}{c}\text { Simulated } \\
P: B \\
\left(y r^{-1}\right)\end{array}$ & Source \\
\hline Bay of Morlaix & 40 & 1.16 & 55.3 & 16.6 & 84.5 & 31.3 & Wafar (1981) \\
\hline Bay of Morlaix & 40 & 0.6 & 63.2 & 16.6 & 187 & 31.3 & L'Helguen (1991) \\
\hline $\begin{array}{l}\text { Stn E1 } \\
\text { (off Plymouth) }\end{array}$ & 70 & 0.91 & 27.3 & 19.8 & 30.4 & 28.6 & $\begin{array}{l}\text { Boalch (1987), } \\
\text { Holligan \& Harbour (1977) }\end{array}$ \\
\hline Straits of Dover & 30 & 3 & 59.2 & 41.3 & 46.7 & 37.4 & Quisthoudt (1987) \\
\hline $\begin{array}{l}\text { Stn Terschelling } 4 \\
\text { (Dutch coast) }\end{array}$ & 10 & 5.52 & 59.3 & & 76.3 & & Peeters et al. (1991) \\
\hline
\end{tabular}


authors. First, a mean annual chlorophyll concentration over the whole water column (b) must be computed and converted into a carbon biomass using a definite $\mathrm{C}$ :chl a ratio. Then, knowing the depth of the station $(H)$, an estimated $P: B$ ratio can be computed using Eq. (30):

$$
P: B=P /[\bar{b} \cdot(\mathrm{C} / \mathrm{chl} a) \cdot H]
$$

In accordance with the assumption made when comparing chlorophyll measurements with computed phytoplanktonic nitrogen concentrations, i.e. that $1 \mu \mathrm{g}$ chl a corresponds to $1 \mu \mathrm{mol}$ phytoplanktonic nitrogen, the value we chose for the $\mathrm{C}$ :chl a ratio is 80 (from $5.68 \times 14=79.52)$. This value is obviously too high for blooming diatom populations, for which values lower than 50 are commonly reported, but fits better with observations made on summer limited populations. In a recent compilation of $219 \mathrm{C}: \mathrm{chl}$ a ratio values measured by several authors in diatom cultures under various nutrient limitations, Cloern et al. (1995) obtain a mean equal to 68.1 , with a standard deviation equal to 65.5 (Cloern pers. comm.); $22 \%$ of the values are above 80 , our empirical value. Moreover, these authors mention, in agreement with Chan (1980), that dinoflagellates have systematically higher $\mathrm{C}: \mathrm{chl}$ a ratios than diatoms, which is favourable to an annual mean value not far from 80 . Of course, use of a varying C:chl a ratio would be a desirable improvement in future models. Finally, some results taken from existing literature are listed in Table 2. They show that for production as well as productivity, the model results are systematically lower than the values estimated from field measurements; the main discrepancy, as explained previously, is found when the value simulated in coastal boxes deep enough to experience thermal stratification is compared to close-to-coast measurements taken in the completely mixed part of the box (box $B$ ). In stratified areas (box A), the simulated production may be underestimated by a 2-layer model during summer, when very dense accumulations of dinoflagellates are observed (Holligan \& Harbour 1977) in the thermocline zone situated between the homogeneous surface and bottom layers. More realistic simulation of these summer episodes would require an integral 3-layer model or a fine vertical resolution. Many other processes, too roughly simulated or omitted from our model, may also explain the insufficient production: lack of nanoplankton, of explicit zooplankton grazing, or of wind-induced episodes of benthic material resuspension. One possible way of improving these large ecosystem models is to test their sensitivity to several components (e.g. process formulation, parameter values, forcing variables or boundary conditions). Conclusions from such a sensitivity analysis are detailed in the companion paper

\section{LITERATURE CITED}

Agoumi A (1985) Modélisation de l'écosystème pélagique en Manche. Etude de l'influence des phénomènes physiques sur le système planctonique. Thèse de doctorat d'état ès Sciences Naturelles. Universite Pierre et Marie Curie Paris

Antia NJ, McAllister CD, Parsons TR, Stephens K, Strickland JDH (1963) Further measurements of primary production using a large-volume plastic sphere. Limnol Oceanogr 8 $166-183$

Armstrong FAJ, Butler EI (1968) Chemical changes in sea water off Plymouth during the years 1962 and 1965. J Mar Biol Ass UK 48:153-160

Baretta-Bekker JG, Riemann B, Baretta JW, Koch-Rasmussen E (1994) Testing the microbial loop concept by comparing mesocosm data with results from a dynamical simulation model. Mar Ecol Prog Ser 106:187-198

Bentley D (1984). Contribution à l'étude hydrobiologıque du détroit du Pas-de-Calais. Paramètres physico-chimiques Thèse de $3^{\text {eme }}$ cycle, Université des Sciences et Techniques de Lille

Bienfang PK (1980) Phytoplankton sinking rates in oligotrophic waters off Hawali, USA. Mar Biol 61:69-77

Boalch GT (1987) Changes in the phytoplankton of the western English Channel in recent years. Br Phycol J 22 $225-235$

Brock TD (1981) Calculating solar radiation for ecological studies. Ecol Modelling 14:1-19

Chan AT (1980) Comparative physiological study of marine diatoms and dinoflagellates in relation to irradiance and cell size. 2. Relationship between photosynthesis, growth and carbon/chlorophyll a ratio. J Phycol 16:428-432

Cloern JE, Grenz C, Vidergar-Lucas L (1995) An empirical model of the phytoplankton chlorophyll:carbon ratio - the conversion factor between productivity and growth rate Limnol Oceanogr 40(7):1313-1321

Eppley RW, Rogers JN, McCarthy JJ (1969) Half-saturation constants for uptake of nitrate and ammonium by marine phytoplankton Limnol Oceanogr 14:912-920

Eppley RW, Rogers JN, McCarthy JJ, Sournia A (1971) Light/ dark periodicity in nitrogen assimilation of the marine phytoplankters Skeletonema costatum and Coccolithus huxleyi in $\mathrm{N}$-limitant chemostat culture. J Phycol 7 : $150-154$

Goujon R, Dupont JP, Meyer R (1992) L'estuaire de la Seine Compte-rendu du colloque national 'Estuaires et Deltas: des milieux menacés?' Bègles, 25 juin 1992. Agence de bassin Adour-Garonne, Toulouse

Harrison PJ, Conway HL, Holmes RW, Davis CO (1977) Manne diatoms grown in chemostats under silicate or ammonium limitation. III. Cellular chemical composition and morphology of Chaetoceros debilis, Skeletonema costatum, and Thalassiosira gravida. Mar Biol 43:19-31

Hoch T, Ménesguen A (1996) Modelling the biogeochemical cycles of elements limiting primary production in the English Channel. II. Sensitivity analyses. Mar Ecol Prog Ser 146:189-205

Hoch T, Ménesguen A, Bentley D (1993) Modelling the nitrogen cycle in the Channel: a first approach. Oceanol Acta 16:643-651

Holligan PM. Harbour DS (1977) The vertical distribution and succession of phytoplankton in the western English Channel in 1975 and 1976. J Mar Biol Ass UK 57:1075-1093

Kamatani A (1971) Physical and chemical characteristics of biogenous silica. Mar Biol 8:89-95

L'Helguen S (1991) Absorption et régénération de l'azote 
dans les écosystèmes pélagiques du plateau continental de la Manche Occidentale. Relations avec le régime de mélange vertıcal des masses d'eau; cas du front thermique d'Ouessant. Thèse de doctorat 'Chimie Appliquée: Chimie Marine', Université de Bretagne Occidentale, Brest

Le Hir P, Bassoulet P, Erard E, Blanchard M, Hamon D, Jégou $A M$, IRIEC (Institut de Recherche en Informatique et Economie) (1986). Etude régionale intégrée du golfe Normand-Breton. 2. Milieu pélagique. Rapport IFREMER/ DERO-EL 86.27, IFREMER, Brest

Le Provost C. Fornerino M (1985) Tidal spectroscopy of the English Channel with a numerical model. J Phys Oceanogr 15:1009-1031

Ménesquen A (1991) 'ELISE', an interactive software for modelling complex aquatic ecosystems. In: Arcilla AS, Pastor $M$, Zienkiewicz OC, Schrefler BA (eds) Computer modelling in ocean engineering 91. Balkema, Rotterdam, p 87-94

Ménesguen A, Guillaud JF, Aminot A, Hoch T (1995) Modelling the eutrophication process in a river plume: the Seine case study (France). Ophelia 42:205-225

Milankovitch $M$ (1930) Mathematische Klimalehre und astronomische Theorie der Klimaschwankungen. Handbuch der Kllmatologie, Band I, Teil A. Cebrüdor Borntraeger, Berlin

Morgan KC, Kalff J (1979) Effect of light and temperature interactions on growth of Cryptomonas erosa (Cryptophyceae). J Phycol 15:127-134

Morin P, Le Corre P, Marty Y, L'Helguen S (1991) Evolution printanière des éléments nutritifs et du phytoplancton sur le plateau continental armoricain (Europe du Nord-Ouest). Oceanol Acta 14:263-279

Mortain-Bertrand A, Descolas-Gros C, Jupin H (1988) Growth, photosynthesis and carbon metabolism in the temperate marine diatom Skeletonoma costatum adapted to low temperature and low photon-flux density. Mar Biol 100:135-141

Niiler PP, Kraus EB (1977) One-dimensional models of the upper ocean. In: Kraus EB (ed) Modelling and prediction of the upper layers of the ocean. Proceedings of a NATO Advanced Study Institute. Pergamon Press, Oxford, p 145-172

Paasche E (1973) Silicon and the ecology of marine plankton diatoms. II. Silicate-uptake kinetics in five diatom species. Mar Biol 19:262-269

Peeters JCH, Haas HA, Peperzak L (1991) Eutrofjering, primary productie en zuurstofhuishouding in de Noordzee. Rijkswaterstaat, Dienst Getijdewateren, nota GWAO91.083, The Hague

Pingree RD, Maddock L (1977) Tidal residuals in the English Channel. J Mar Biol Ass UK 57:339-354

Pingree RD, Maddock L. (1985) Stokes, Euler and Lagrange aspects of residual tidal transports in the English Channel and the southern bight of the North Sea. J Mar Biol Ass UK $65: 969-982$

This article was submitted to the editor
Pingree RD, Maddock L, Butler El (1977) The influence of biological activity and physical stability in determining the chemical distributions of inorganic phosphate, silicate and nitrate. J Mar Biol Ass UK 57:1065-1073

Prestidge MC. Taylor AH (1995) A modelling investigation of the distribution of stratification and phytoplankton abundance in the Irish Sea. J Plankton Res 17(7):1397-1420

Quisthoudt C (1987) Production primaire phytoplanctonique dans le detroit du Pas-de-Calais (France): variations spatiales et annuelles au large du Cap Gris-Nez. CR Acad Sci Paris 10(3):245-250

Riley GA (1975) Transparency-chlorophyll relations. Limnol Oceanogr 20:150-1.52

Riou J (1990) Modèle d'écosystème phytoplanctonique marin sur le littoral nord-breton (Manche Occidentale). Thèse de doctorat 'Physique et Chimie de l'Environnement', Institut National Polytechnique de Toulouse

Ross AH, Gurney WSC, Heath MR, Hay SJ, Henderson EW (1993) A strategic simulation model of a fjord ecosystem. Limnol Oceanogr 38:128-153

Ryther JH (1956) Photosynthesis in the ocean as a function of light intensity. Limnol Oceanogr 1:61-70

Salomon JC, Breton M (1991) Courants de marée et courants résiduels dans la Manche. Oceanol Acta 11:47-53

Salomon JC, Breton M (1993) An atlas of long-term currents in the Channel. Oceanol Acta 16:439-448

Salomon JC, Guéguéniat P, Orbi A, Baron Y (1988) A lagrangian model for long term tidally induced transport and mixing. Verification by artificial radionucleide concentrations. In: Guary JC, Guéguéniat P, Pentreath RI (eds) Radionucleides: a tool for oceanography. Elsevier Applied Science, London, p 384-394

Smayda TJ (1970) The suspension and sinking of phytoplankton in the sea. Oceanogr Mar Biol A Rev 8:353-414

Steele $\mathrm{JH}$ (1962) Environmental control of photosynthesis in the sea. Limnol Oceanogr 7:137-150

Taylor AH, Reid PC, Marsh TJ, Jonas TD, Stephens JA (1981) Year-to-year changes in the salinity of the eastern English Channel, 1948-1973: a budget. J Mar Biol Ass UK 61 $489-507$

Tett P (1990) A three layer vertical and microbiological processes model for shelf seas. Proudman Oceanographic Laboratory Rept 14

Vinogradov MY, Krapivin VF, Menshutkin VV, Fleyshman BS, Shushkina EA (1973) Mathematical model of the functions of the pelagial ecosystem in tropical regions (from the 50th voyage of the R/V 'VITYAZ'). Oceanology 13 $704-717$

Wafar M (1981) Nutrients, primary production, and dissolved and particulate organic watter in well-mixed temperate coastal waters (Bay of Morlaix-Western English Channel). Thèse de $3^{\text {éme }}$ cycle, Unıversité Paris Vı

Manuscript first received: July 20,1995

Revised version accepted: October 10, 1996 